\title{
Correlation of clinical and ultrasonographic features with histopathology in post-menopausal bleeding
}

\author{
Meenakshi Vempalli, Lopamudra B. John*, G. Chandana
}

Department of Obstetrics and Gynecology, Mahatma Gandhi Medical College and Research Institute, Pondicherry, India

Received: 22 April 2020

Accepted: 28 May 2020

\section{*Correspondence:}

Dr. Lopamudra B. John,

E-mail: drlopamdpondy@yahoo.com

Copyright: () the author(s), publisher and licensee Medip Academy. This is an open-access article distributed under the terms of the Creative Commons Attribution Non-Commercial License, which permits unrestricted non-commercial use, distribution, and reproduction in any medium, provided the original work is properly cited.

\begin{abstract}
Background: Postmenopausal bleeding is generally regarded as an ominous alarm of genital pathologies which requires a thorough evaluation clinically and pathologically to exclude carcinoma as the cause and ensure a benign pathology. This study aims at finding out whether clinical diagnosis and ultrasonographic features can be reliable parameters for the diagnosis of causes and whether the findings correspond with histopathology reports.

Methods: This observational study was conducted in a tertiary care centre in Pondicherry between January 2018 to August 2019. 114 women were enrolled for whom detailed history taking and clinical examination was done. All the patients were subjected to transvaginal ultrasonography. Patients with clinically visible lesions on cervix and vulva were subjected to biopsy and the rest underwent fractional curettage and the sample was sent for histopathological examination. Finally, histopathology report was compared with clinical and ultrasonographic findings.

Results: With endometrial thickness cut off of $4 \mathrm{~mm}$, the sensitivity, specificity, positive predictive value and negative predictive value in predicting malignancy by ultrasonography were $100 \%, 12.3 \%, 4.5 \%$ and $100 \%$. Histopathology showed atrophic endometrium (43.8\%), endometrial hyperplasia (8\%), endometrial polyp (7.9\%) and endometrial carcinoma (3\%). Clinical and ultrasonographic findings did not show any statistical correlation with histopathology.

Conclusions: Authors conclude that clinical findings and ultrasonographic features do not correlate with histopathology in cases of postmenopausal bleeding for which atrophic endometrium was the commonest etiology. However, ultrasound should be done routinely before endometrial sampling as the sensitivity for predicting malignancy was $100 \%$ for endometrial thickness cut off of $4 \mathrm{~mm}$.
\end{abstract}

Keywords: Endometrial thickness, Postmenopausal bleeding, Ultrasonography

\section{INTRODUCTION}

With increasing life expectancy, a healthy 50-year-old woman today spends as much as $40 \%$ of her life in postmenopausal state. During this prolonged period, they are vulnerable to various conditions, of which one of the prime importance and sincere concern is postmenopausal bleeding. ${ }^{1}$

Postmenopausal bleeding is a common clinical condition with an incidence of $10 \% .^{2}$ It represents approximately
$5 \%$ of all gynaecological visits and is generally regarded as an ominous and serious alarm of genital pathologies. ${ }^{3}$ The dictum is 'postmenopausal bleeding indicates malignancy unless proved otherwise'. According to Indian cancer registry, there is an increasing trend for corpus uteri malignancies in the past two decades. ${ }^{4}$ About $90 \%$ of patients with endometrial carcinoma presents with postmenopausal bleeding however, only $10 \%$ with this symptom have endometrial carcinoma. ${ }^{5,6}$ Clinical evaluation should include abdominal. speculum and bimanual examination to assess atrophic vaginitis and to 
rule out tumors of cervix, vagina, vulva or cervical polyps. Transvaginal ultrasonography is often recommended as the preliminary non-invasive investigation for assessing endometrial thickness and morphology in women with postmenopausal bleeding. The gold standard for diagnosis of any malignancy is tissue biopsy.

This study aims at finding out whether clinical diagnosis and ultrasonographic features can be reliable parameters for the diagnosis of causes of postmenopausal bleeding of which malignancy is one of the important causes and whether the findings correspond with histopathology reports.

\section{METHODS}

This was an observational study conducted in Mahatma Gandhi Medical College and Hospital, a tertiary care centre in Pondicherry over a period of 18 months from January 2018 to August 2019.

\section{Inclusion criteria}

- The women with postmenopausal bleeding who fulfilled the inclusion criteria and willing to participate in the study were recruited after written and informed consent.

\section{Exclusion criteria}

- Women who were known cases of bleeding disorders, liver disease, on anticoagulant therapy, currently on hormonal therapy and treated cases of genital malignancy were excluded.

A total number of 114 women were enrolled for the study. The patients were clinically evaluated by detailed history and examination and a provisional diagnosis was made. Patients with clinically visible local lesions on the cervix and vulva were subjected to biopsy. All the patients were subjected to transvaginal ultrasound examination and endometrial thickness, uterine lesion and adnexal pathology if any were noted. All the patients without any visible cervical or vulval lesions were subsequently subjected to fractional curettage irrespective of endometrial thickness in ultrasonography and sample was sent for histopathological examination. Finally, histopathology report was compared with clinical and ultrasonographic findings.

\section{Statistical analysis}

Statistical analysis was carried out using SPSS version 19.0 (IBM SPSS, US) software with regression modules installed. Clinical findings, ultrasonographic features and histopathology are summarized as percentages and were further categorized into normal, benign, premalignant, malignant lesions. Agreement of diagnosis between clinical findings with histopathology and ultrasonography with histopathology of minor procedures were estimated using kappa statistics. Kappa more than 0.5 was considered to be significant. Sensitivity, specificity, positive predictive value and negative predictive value were calculated for clinical examination and endometrial thickness for predicting malignancy.

\section{RESULTS}

In this study, age range of women with postmenopausal bleeding was $42-78$ years and mean age was 56.25 years. Maximum number of cases $48(42.1 \%)$ were obese followed by normal BMI in $30(26.3 \%)$ patients. Regarding co morbidities, $42(36.8 \%)$ patients had hypertension, $38(33.3 \%)$ had diabetes mellitus, 10 $(8.8 \%)$ had hypothyroidism, $4(3.5 \%)$ patients had hypercholesterolemia and $4(3.5 \%)$ had bronchial asthma.

Table 1: Findings by clinical examination (categorised).

\begin{tabular}{|lll|}
\hline Overall clinical findings & $\mathbf{N}$ & $\%$ \\
\hline Normal & 51 & $44.8 \%$ \\
\hline Infection/inflammation & 13 & $11.4 \%$ \\
\hline Benign & 45 & $39.4 \%$ \\
\hline Malignant & 3 & $2.6 \%$ \\
\hline Others & 2 & $1.8 \%$ \\
\hline Total & 114 & $100 \%$ \\
\hline
\end{tabular}

Table 2: USG findings (categorised).

\begin{tabular}{|lll|}
\hline Overall findings by USG & $\mathbf{N}$ & $\%$ \\
\hline Benign & 18 & $15.8 \%$ \\
\hline Malignant & 4 & $3.5 \%$ \\
\hline Normal & 92 & $80.7 \%$ \\
\hline Total & 114 & $100 \%$ \\
\hline
\end{tabular}

Table 3: Histopathological findings in minor procedures (categorised).

\begin{tabular}{|lll|}
\hline HPE findings (categorized) & $\mathbf{N}$ & $\%$ \\
\hline Normal & 60 & $52.6 \%$ \\
\hline Premalignant endometrial & 10 & $8.7 \%$ \\
\hline Malignant endometrial & 4 & $3.5 \%$ \\
\hline Benign endometrial polyp & 8 & $7.0 \%$ \\
\hline Nil curetting's & 17 & $14.9 \%$ \\
\hline Malignant cervical & 2 & $1.7 \%$ \\
\hline Premalignant cervical & 3 & $2.6 \%$ \\
\hline Benign endocervical polyp & 3 & $2.6 \%$ \\
\hline Malignant vaginal & 1 & $0.9 \%$ \\
\hline Others & 6 & $5.2 \%$ \\
\hline Total & 114 & $100 \%$ \\
\hline
\end{tabular}

The clinical findings included benign lesions like fibroids, genital prolapse related findings like cystocoele and rectocele, cervical polyps and clinically benign ovarian cysts. Findings of cervical erosions and vaginal discharge were taken to be of infectious or inflammatory 
origin. A total of three lesions, two cervical and one vaginal growth were suspected to be malignant. A total of $51(44.8 \%)$ cases appeared normal clinically followed by $45(39.4 \%)$ cases with benign lesions and $3(2.6 \%)$ cases of suspected malignancy (Table 1). The sensitivity, specificity, positive predictive value and negative predictive values of clinical findings in predicting malignancy were $22.2 \%, 98.1 \%, 66.7 \%$ and $93.7 \%$ respectively.

Ultrasound findings were categorised as benign including fibroid and adenomyosis in 7 cases each, 3 cases of endocervical polyp and 1 case of fibroid polyp, a total of $18(15.8 \%)$ cases. Malignancy was suspected in a total of $4(3.5 \%)$ cases which included 3 cases of endometrial and 1 case of cervical mass (Table 2). In the present study, endometrial thickness ranged from $2-30 \mathrm{~mm}$. The mean endometrial thickness was $9.51 \mathrm{~mm}$. There were 13 patients with endometrial thickness less than or equal to 4 $\mathrm{mm}$. Keeping $4 \mathrm{~mm}$ as endometrial thickness cut off by ultrasonography, sensitivity, specificity, positive predictive value and negative predictive value in predicting malignancy were $100 \%, 12.3 \%, 4.5 \%$ and $100 \%$ respectively.

Table 4: Comparison of clinical findings with HPE from minor procedures.

\begin{tabular}{|c|c|c|c|c|c|c|c|c|c|c|c|c|}
\hline \multicolumn{13}{|c|}{ HPE findings from minor procedures } \\
\hline 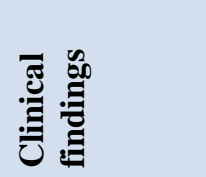 & 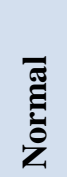 & $b^{\circ}$ & صే & $0^{\circ}$ & 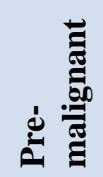 & $0^{\circ}$ & 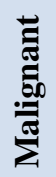 & $0^{\circ}$ & 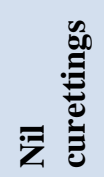 & $0^{\circ}$ & $\stackrel{\bar{\sigma}}{\stackrel{\pi}{\theta}}$ & $b^{\circ}$ \\
\hline Normal & 31 & $52.5 \%$ & 5 & $31.3 \%$ & 7 & $46.7 \%$ & 1 & $14.3 \%$ & 7 & $41.2 \%$ & 51 & $44.7 \%$ \\
\hline $\begin{array}{l}\text { Infection/ } \\
\text { inflammation }\end{array}$ & 6 & $10.2 \%$ & 1 & $6.3 \%$ & 4 & $26.7 \%$ & 2 & $28.6 \%$ & 0 & $0.0 \%$ & 13 & $11.4 \%$ \\
\hline Benign & 22 & $37.3 \%$ & 7 & $43.8 \%$ & 4 & $26.7 \%$ & 2 & $28.6 \%$ & 10 & $58.8 \mathrm{v}$ & 45 & $39.5 \%$ \\
\hline Malignant & 0 & $0.0 \%$ & 1 & $6.3 \%$ & 0 & $0.0 \%$ & 2 & $28.6 \%$ & 0 & $0.0 \%$ & 3 & $2.6 \%$ \\
\hline Others & 0 & $0.0 \%$ & 2 & $12.5 \%$ & 0 & $0.0 \%$ & 0 & $0.0 \%$ & 0 & $0.0 \%$ & 2 & $1.8 \%$ \\
\hline Total & 59 & $100 \%$ & 16 & $100 \%$ & 15 & $100 \%$ & 7 & $100 \%$ & 17 & $100 \%$ & 114 & $100 \%$ \\
\hline
\end{tabular}

chi square $=46.4$, Measure of agreement (kappa): 0.072 .

Table 5: Comparison of USG findings with HPE from minor procedures.

HPE findings from minor procedures

\begin{tabular}{|c|c|c|c|c|c|c|c|c|c|c|c|c|}
\hline 司 & हु & $a^{2}$ & 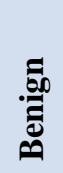 & $0^{0}$ & 总 & $a^{0}$ & 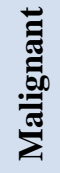 & $x^{0}$ & $\overline{\bar{z}}$ & $2^{\circ}$ & $\stackrel{\bar{\sigma}}{\tilde{0}}$ & $a^{\circ}$ \\
\hline Benign & 14 & $23.7 \%$ & 4 & $25 \%$ & 6 & $40 \%$ & 4 & $57.2 \%$ & 6 & $35.3 \%$ & 34 & $29.8 \%$ \\
\hline Malignant & 0 & $0.0 \%$ & 1 & $6.3 \%$ & 1 & $6.7 \%$ & 1 & $14.2 \%$ & 1 & $5.8 \%$ & 4 & $3.5 \%$ \\
\hline Normal & 45 & $76.3 \%$ & 11 & $68.7 \%$ & 8 & $53.3 \%$ & 2 & $28.6 \%$ & 10 & $58.9 \%$ & 76 & $66.7 \%$ \\
\hline Total & 59 & $100 \%$ & 16 & $100 \%$ & 15 & $100 \%$ & 7 & $100 \%$ & 17 & $100 \%$ & 114 & $100 \%$ \\
\hline Benign & 14 & $23.7 \%$ & 4 & $25 \%$ & 6 & $40 \%$ & 4 & $57.2 \%$ & 6 & $35.3 \%$ & 34 & $29.8 \%$ \\
\hline Malignant & 0 & $0.0 \%$ & 1 & $6.3 \%$ & 1 & $6.7 \%$ & 1 & $14.2 \%$ & 1 & $5.8 \%$ & 4 & $3.5 \%$ \\
\hline
\end{tabular}

Pearson chi2(8) =11.6394 Measure of agreement (kappa): 0.05 .

Biopsy was taken in all 114 patients who presented with postmenopausal bleeding. 9 cases had obvious extrauterine lesions from which biopsy was taken. All the rest 105 cases underwent endometrial biopsy. Regarding the biopsy reports, malignancy was detected in 7 patients, carcinoma endometrium was found in 4 patients $(3.5 \%)$, cervical carcinoma in 2 cases $(1.8 \%)$ and vaginal carcinoma was there in $1(0.9 \%)$ patient. Pre-malignancy was reported in 10 cases with endometrial biopsy, simple hyperplasia without atypia being the commonest in 5 cases, simple hyperplasia with atypia in 1 patient, complex hyperplasia with atypia in 1 case and 3 cases of high grade squamous intraepithelial lesion was reported in cervical biopsy finding. A total of 60 cases had benign findings in endometrial biopsy with atrophic endometrium being the commonest cause comprising of total $49(42.9 \%)$ cases, 5 cases of proliferative phase endometrium and 4 cases of secretory endometrium. 6 cases of benign endometrial polyp and 3 cases of endocervical polyp were reported. 17 cases did not reveal any tissue during endometrial biopsy (Table 3 ). 
The correlation between the clinical findings and histopathology of minor procedures showed that there were 3 cases which were clinically malignant, whose histopathology showed only two malignancies of squamous cell carcinoma of vagina and squamous cell carcinoma of cervix. A total of 7 malignancies were found in histopathology. So, 5 malignancies were missed by clinical examination. These were carcinoma endometrium in 4 patients and carcinoma cervix in 1 patient. The measurement of agreement (kappa) was 0.072 , hence the clinical findings did not correlate with histopathology (Table 4).

The correlation between the ultrasonography and histopathology of minor procedures showed that there were 4 cases which were diagnosed malignant through ultrasonography, whose histopathology showed positive for only 1 malignancy that is endometrial cancer. A total of 7 patients were found malignant through histopathology, hence USG failed to detect 6 other cases. These cases were endometrial carcinoma in 3 patients, carcinoma cervix in 2 patients and vaginal cancer in 1 patient. The measurement of agreement (kappa) was 0.05 , hence the ultrasonographic features did not correlate with histopathology (Table 5).

\section{DISCUSSION}

In the present study, the maximum number of cases $(30 \%)$ were in the age group of $42-50$ years and $19 \%$ cases were in the age group of 56-60 years while in a study by Jadoon et al, the commonest age group was 61 to 70 years seen in 19 cases $(54.3 \%){ }^{7}$ The mean age in this study was 56.25 years which was in contrast with a study by Escoffery et al where mean age was 63.6 years. ${ }^{8}$

In the present study though maximum number of cases of $46(40.4 \%)$ patients had normal BMI, a significant number of 36 patients $(31.6 \%)$ were obese which was in comparison with a study done by Kant et al where $34.5 \%$ patients were obese but in contrast to Syeda et al, study where obesity was found in $72.7 \%$ cases. ${ }^{9,10}$ Regarding the comorbidities, in the present study, 42 (36.8\%) patients had hypertension and $38(33.3 \%)$ had diabetes mellitus. Similar, high numbers were found in the study by Syeda et al, where they reported $54.5 \%$ cases of diabetes mellitus and $27.3 \%$ cases with hypertension. ${ }^{10}$ This was in contrast to other studies by Kant et al and Jadoon et al, where diabetes and hypertension were found in $12(10.3 \%)$ and $35(30.2 \%)$ cases and $12(35 \%)$ and 7 $(20 \%)$ cases respectively. ${ }^{7,9}$

Regarding the clinical findings related to uterus, maximum of 90 (78.9\%) patients had no pathology. This was in contrast with the study conducted by Kant et al, where only $45.7 \%$ patients had no pathology. ${ }^{9}$

Ultrasonographic measurement of endometrial thickness is an important tool for evaluation of postmenopausal bleeding. In the present study, endometrial thickness ranged from 2-30 $\mathrm{mm}$. In a study by Burbos et al, a greater number of women had endometrial thickness less than $5 \mathrm{~mm}$ which was in contrast to the present study where a greater number of women had endometrial thickness more than or equal to $5 \mathrm{~mm} .{ }^{11}$ In the study by Vilasiny et al, maximum patients had endometrial thickness more than $4 \mathrm{~mm} .{ }^{12}$ In 2013 , Kothapally et al found that in $80 \%$ of patients, endometrial thickness on ultrasound was more than $4 \mathrm{~mm}$ which was similar to the present study. ${ }^{13}$ The mean endometrial thickness was 9.51 $\mathrm{mm}$ in the present study which was almost similar to a study conducted by Kaur et al where the mean endometrial thickness in patients with postmenopausal bleeding was $8.21 \pm 6.88 \mathrm{~mm} .{ }^{14}$

In a study by Gerber et al, endometrial thickness was 10 $\mathrm{mm}$ or more in $55.2 \%$ of cases with endometrial carcinoma similar to the present study where endometrial thickness was $10 \mathrm{~mm}$ or more in $100 \%$ of cases with endometrial carcinoma. ${ }^{15}$ In the present study, no woman with endometrial cancer had endometrial thickness less than or equal to $4 \mathrm{~mm}$. This was similar to another study by Gull et al where no women with endometrial cancer had endometrial thickness of less than or equal to $4 \mathrm{~mm} .{ }^{16}$ Karlsson et al found that malignant endometrium was never less than $5 \mathrm{~mm}$ which was in concordance to the present study. ${ }^{17}$ Lewin et al investigated 50 women with postmenopausal bleeding. The endometrial thickness was $>5 \mathrm{~mm}$ in 32 patients and 22 among them had pathologies in endometrium, out of which 16 had benign changes and 6 had endometrial cancer. Eighteen patients among postmenopausal bleeding group with endometrial thickness $<5 \mathrm{~mm}$ had normal endometrium. Hence, in detecting endometrial malignancy, endometrial thickness $>5 \mathrm{~mm}$ was $100 \%$ sensitive and $64 \%$ specific whereas in the present study, in detecting endometrial malignancy, ET $>4 \mathrm{~mm}$ was $100 \%$ sensitive but only $12.3 \%$ specific. $^{18}$ In the present study, women with endometrial thickness of less than or equal to $4 \mathrm{~mm}$ had endometrial atrophy which was similar to Ferrazzi et al, who conducted a prospective study on 930 patients and concluded that endometrial thickness of less than or equal to $4 \mathrm{~mm}$ predicts it as endometrial atrophy and needs only expectant management avoiding invasive procedures and also does not delay in cancer diagnosis. ${ }^{19}$ Conoscenti et al found that though endometrial thickness cut off for defining normal endometrium was $4 \mathrm{~mm}$, in patients with $<4 \mathrm{~mm}$ endometrial thickness, one case of malignancy was diagnosed. ${ }^{20}$ Similarly, Philip et al, opined that correlation between ultrasonography and histopathology was not reliable, this is because half of the women with endometrial cancer had endometrial thickness of 3-4 mm and $70 \%$ women with benign pathology had endometrial thickness of $>5 \mathrm{~mm} .{ }^{21}$ This was in contrast with the present study where cases with endometrial hyperplasia and carcinoma had endometrial thickness of more than or equal to $10 \mathrm{~mm}$.

Among the 114 patients who presented with postmenopausal bleeding 9 cases had obvious 
extrauterine lesions from which biopsy was taken and the rest 105 cases underwent endometrial biopsy. In the present study, it was observed that atrophic endometrium was the most common histological diagnosis i.e in 50 cases $(43.8 \%)$. The incidence of atrophy was found to be $49.9 \%$ by Gredmark T et al, $52.1 \%$ by Lee et al, $53 \%$ by Kaur et al and $64.4 \%$ by Dangal et al. ${ }^{14,22-24}$ In contrast Caspi et al, Bani et al, Kothapally et al found atrophic endometrium as the second commonest finding and Philip et al found atrophic endometrium $13.3 \%$ as the third most common cause after proliferative endometrium. ${ }^{13,21,25,26}$

Dawood et al found atrophic endometrium and vaginitis in 33 patients $(21.2 \%)$ and genital tract malignancies in $16 \%$ cases in contrast to the present study where atrophic endometrium was there in 50 cases $(43.8 \%)$ and genital tract malignancies in $7(6.2 \%) .{ }^{27}$ In a study by Doorn et al and Sadia et al, malignancy was present in $10 \%$ and $30 \%$ respectively in contrast to $6.1 \%$ in the present study. ${ }^{28,29}$ In a study by Choo et al, atrophic endometrium was found in $82 \%$, proliferative endometrium in $7 \%$ and secretory endometrium in $1 \%$ of patients. ${ }^{30}$ Carcinoma was uncommon, found in only $7 \%$ of patients and was similar to the present study.

\section{CONCLUSION}

Based on the observations from this study, authors conclude that clinical findings and ultrasonographic features do not correlate with histopathology in cases of postmenopausal bleeding. However, a thorough clinical examination is essential in the initial assessment of women with this symptom. Ultrasound which is a simple, non-invasive and cost-effective tool should be used as a routine investigation in the evaluation of such cases and should be performed before subjecting the patient for endometrial sampling as endometrial thickness of $<4 \mathrm{~mm}$ did not yield any premalignant and malignant finding in histopathology. The most common cause of postmenopausal bleeding was found to be atrophic endometrium.

Funding: No funding sources

Conflict of interest: None declared

Ethical approval: The study was approved by the Institutional Ethics Committee

\section{REFERENCES}

1. Olshansky SJ, Carnes BA, Cassel CK. The aging of the human species. Sci Am. 1993;268(4):46-52.

2. Astrup K, Olivarius $\mathrm{N}$ de $\mathrm{F}$. Frequency of spontaneously occurring postmenopausal bleeding in the general population. Acta Obstet Gynecol Scand. 2004;83(2):203-7.

3. Moodley M, Roberts C. Clinical pathway for the evaluation of postmenopausal bleeding with an emphasis on endometrial cancer detection. J Obstet Gynaecol. 2004;24(7):736-41.
4. Yeole B. Trends in cancer incidence in female breast, cervix uteri, corpus uteri, and ovary in India. Asian Pac J Cancer Prev. 2007;9:119-22.

5. Bokhman JV. Two pathogenetic types of endometrial carcinoma. Gynecol Oncol. 1983;15(1):10-7.

6. Wong SF, Luk KL, Wong AY, Tang LC. Findings in women with postmenopausal bleeding investigated with hysteroscopy. J Inst Obstet Gynaecol. 2001;21(4):392-5.

7. Jadoon S, Khan SM, Qadir M, Bibi N. postmenopausal bleeding - a strong indicator of endometrial carcinoma. Pak Armed Forces Med J. 2019;69(2):368-72.

8. Escoffery CT, Blake GO, Sargeant LA. Histopathological findings in women with postmenopausal bleeding in Jamaica. West Indian Med J. 2002;51(4):232-5.

9. Kant RH, Iqbal A, Rather SY, Sharma P. Postmenopausal bleeding, endometrial curretage, endometrial hyperplasia, endo-metrial carcinoma, atrophic endometrium. significance Clin Histopathol Eval. 2015;42(4):7371-80.

10. Fatima SS, Naib JM, Sharafat Z, Mazhar T. Postmenopausal bleeding- an alarming symptom of endometrial carcinoma. J Med Sci. 2014;22(4):16670 .

11. Burbos N, Musonda P, Giarenis I, Shiner AM, Giamougiannis P, Morris E, et al. Age-related differential diagnosis of vaginal bleeding in postmenopausal women: a series of 3047 symptomatic postmenopausal women. Menopause Int. 2010;16(1):5-8.

12. Narayanan V, Nair R. Evaluation of Endometrium in Postmenopausal bleeding women. Obs Gyne Rev J. 2016;2:3.

13. Fatima SS, Naib JM, Sharafat Z, Mazhar T. Postmenopausal bleeding- an alarming symptom of endometrial carcinoma. J Med Sci. 2014;22(4):16670.

14. Kaur M, Singh R, Sharma M. Endovaginal sonographic evaluation of postmenopausal uterine bleeding. J Clin Diagnos Res. 2010;(4):2175-82.

15. Gerber B, Krause A, Kuelz T, Quasmeh A, Reimer $\mathrm{T}$, Friese K. Rating of transvaginal sonography in the evaluation of postmenopausal bleeding. Zentralbl Gynakol. 1999;121(3):143-8.

16. Gull B, Karlsson B, Milsom I, Granberg S. Factors associated with endometrial thickness and uterine size in a random sample of postmenopausal women. Am J Obstet Gynecol. 2001;185(2):386-91.

17. Karlsson B, Granberg S, Wikland M, Ylöstalo P, Torvid K, Marsal K, et al. Transvaginal ultrasonography of the endometrium in women with postmenopausal bleeding-a nordic multicenter study. Am J Obstet Gynecol. 1995;172(5):1488-94.

18. Lewin A, Gabis L, Ushakov F, Anteby SA. Endometrial measurement by transvaginal sonography in postmenopausal bleeding. Harefuah. 1996;130(10):662-8. 
19. Ferrazzi E, Torri V, Trio D, Zannoni E, Filiberto S, Dordoni D. Sonographic endometrial thickness: a useful test to predict atrophy in patients with postmenopausal bleeding. An Italian multicenter study. J Int Soc Ultrasound Obstet Gynecol. 1996;7(5):315-21.

20. Conoscenti G, Meir YJ, Fischer-Tamaro L, Maieron A, Natale R, D'Ottavio G, et al. Endometrial assessment by transvaginal sonography and histological findings after $\mathrm{D}$ and $\mathrm{C}$ in women with postmenopausal bleeding. J Int Soc Ultrasound Obstet Gynecol. 1995;6(2):108-15.

21. Phillip H, Dacosta V, Fletcher H, Kulkarni S, Reid M. Correlation between transvaginal ultrasound measured endometrial thickness and histopathological findings in Afro-Caribbean Jamaican women with postmenopausal bleeding. J Inst Obstet Gynaecol. 2004;24(5):568-72.

22. Gredmark T, Kvint S, Havel G, Mattsson LA. Histopathological findings in women with postmenopausal bleeding. Int $\mathrm{J}$ Obstet Gynaecol. 1995;102(2):133-6.

23. Lee WH, Tan KH, Lee YW. The aetiology of postmenopausal bleeding-a study of 163 consecutive cases in Singapore. Singapore Med J. 1995;36(2):164-8.

24. Dangal G. A study of endometrium of patients with abnormal uterine bleeding at Chitwan Valley. Kathmandu Univ Med J. 2002;1:110-2.

25. Caspi E, Perpinial S, Reif A. Incidence of malignancy in Jewish women with postmenopausal bleeding. Isr J Med Sci. 1977;13(3):299-304.
26. Bani-Irshaid I, Al-Sumadi A. Histological findings in women with postmenopausal bleeding: Jordanian figures. Eastern Mediterranean Health J. 2011;17(7):582-62.

27. Dawood NS, Peter K, Ibrar F, Dawood A. Postmenopausal bleeding: causes and risk of genital tract malignancy. J Ayub Med Coll Abbottabad. 2010;22(2):117-20.

28. Van Doorn LC, Dijkhuizen FPHLJ, Kruitwagen RFMP, Heintz APM, Kooi GS, Mol BWJ, et al. Accuracy of transvaginal ultrasonography in diabetic or obese women with postmenopausal bleeding. Obstet Gynecol. 2004;104(3):571-8.

29. Khan S, Hameed S, Umber A. Histopathological pattern of endometrium on diagnostic $\mathrm{D}$ and $\mathrm{C}$ in patients with abnormal uterine bleeding. Ann. 2011;17(2):166-70.

30. Choo YC, Mak KC, Hsu C, Wong TS, Ma HK. Postmenopausal uterine bleeding of nonorganic cause. Obstet Gynecol. 1985;66(2):225-8.

Cite this article as: Vempalli M, John LB, Chandana G. Correlation of clinical and ultrasonographic features with histopathology in post-menopausal bleeding. Int J Reprod Contracept Obstet Gynecol 2020;9:2817-22. 